\title{
SÍNDROME MASCARADA POR RETINOBLASTOMA DIFUSO
}

\section{UVEITIS MASQUERADE SYNDROME PRESENTING AS A DIFFUSE RETINOBLASTOMA}

\author{
CATALÀ-MORA J ${ }^{1}$, PARAREDA-SALLES A ${ }^{2}$, VICUÑA-MUÑOZ CG ${ }^{1}$, MEDINA-ZURINAGA M³ \\ PRAT-BARTOMEU J ${ }^{4}$
}

\begin{abstract}
RESUMEN
Caso clínico: Paciente de tres años con sospecha de uveítis intermedia. La exploración oftalmológica, ecografía ocular, resonancia nuclear magnética y tomografía computerizada orbitaria no fueron concluyentes. La determinación de la tasa de lactato deshidrogenasa (LDH) en humor acuoso/suero fue la clave para llegar al diagnóstico de un retinoblastoma difuso.

Discusión: El síndrome mascarada es la forma de debut en un 1-3\% de los retinoblastomas. La punción de cámara anterior está contraindicada en pacientes con retinoblastoma pero podría ser la única forma de llegar a un diagnóstico correcto en estos casos difíciles y poco frecuentes. Las pruebas enzimáticas como la LDH nos ofrecen una buena sensibilidad y especificidad para el diagnóstico de estos pacientes.
\end{abstract}

Palabras clave: Uveítis intermedia, LDH, mascarada, retinoblastoma.

\begin{abstract}
Clinic report: A 3-year-old boy presented with an intermediate uveitis. Complete ophthalmic exam, ocular ultrasonography, magnetic resonance imaging and computerized tomography of the orbit were inconclusive. Determination of the aqueous humor/serum rate of Lactate dehydrogenase (LDH) was the key for the diagnosis of a diffuse retinoblastoma.

Discussion: A masquerade syndrome is the initial presentation in 1-3\% of retinoblastomas. Aqueous humor punction is contraindicated in patients with retinoblastoma but it might be the only way to achieve a correct diagnosis in these difficult and very unusual cases: enzymatic assays such as LDH offer a good sensitivity and specificity for the diagnosis of these patients (Arch Soc Esp Oftalmol 2009; 84: 477-480).
\end{abstract}

Key words: Intermediate uveitis, LDH, masquerade, retinoblastoma.

\footnotetext{
Recibido: 25/2/08. Aceptado: 23/9/09.

Unitat de Retinoblastoma. Hospital Sant Joan de Déu. Esplugues de Llobregat. Barcelona.

${ }^{1}$ Licenciado en Medicina. Servicio de Oftalmología.

2 Doctor en Medicina. Servicio de Oncología Pediátrica.

3 Licenciado en medicina. Servicio de Anatomía Patológica.

${ }^{4}$ Doctor en Medicina. Servicio de Oftalmología.

Comunicación presentada parcialmente en el 20 Congreso del GEMU (Madrid 2007).

Correspondencia:

Jaume Català Mora

C/. Puríssima Concepció, 2, 2-1

08004 Barcelona

España

E-mail: info@jaumecatala.com
} 


\section{INTRODUCCIÓN}

Los retinoblastomas difusos son poco frecuentes y difíciles de diagnosticar. Estos tumores se pueden manifestar en forma de reacción inflamatoria intraocular produciendo cuadros de uveítis con presencia de acúmulos de células tumorales simulando un hipopión. El tratamiento habitual consiste en la enucleación del ojo afecto. La severidad del diagnóstico ha planteado el desarrollo de diferentes pruebas para confirmar el diagnóstico antes de la enucleación. La determinación de LDH en humor acuoso puede ser útil en el manejo de estos casos.

\section{CASO CLÍNICO}

Un niño de tres años fue remitido a nuestro servicio con sospecha de uveítis anterior del ojo izquierdo refractaria al tratamiento tópico. El paciente no presentaba antecedentes personales ni familiares de interés. La exploración con lámpara de hendidura mostraba una marcada celularidad en cámara anterior con un hipopión de $1 \mathrm{~mm}$. Presentaba también un tyndall celular vítreo así como una lesión blanca de unos $2 \mathrm{~mm}$ de diámetro en la pars plana (fig. 1). El ojo contralateral era normal.

Se realizó una ecografía ocular que no detectó calcio intralesional (fig. 2). La resonancia nuclear magnética mostró la lesión temporal superior y la tomografía computerizada detectó una mínima calcificación intralesional (fig. 3). Se decidió realizar

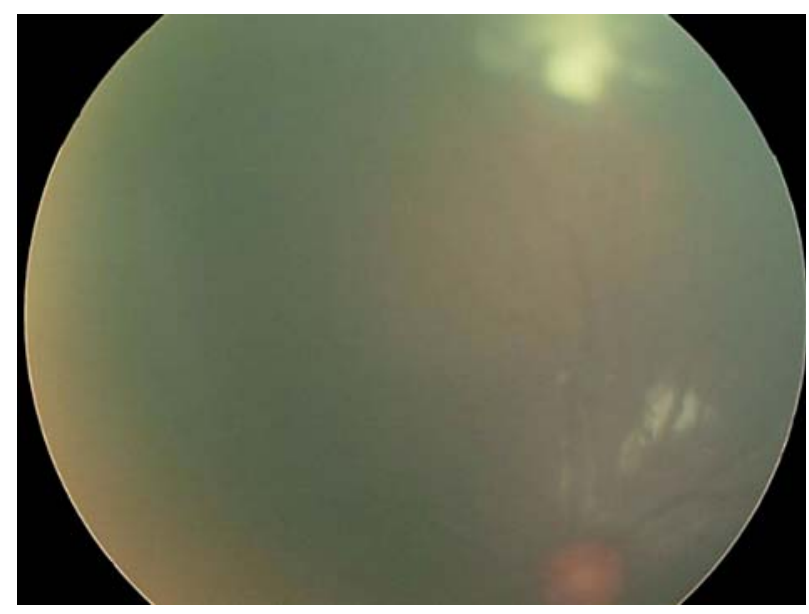

Fig. 1: Imagen de fondo de ojo izquierdo en la que se aprecia el tyndall vítreo junto con una lesión blanca de $2 \mathrm{~mm}$ de diámetro.

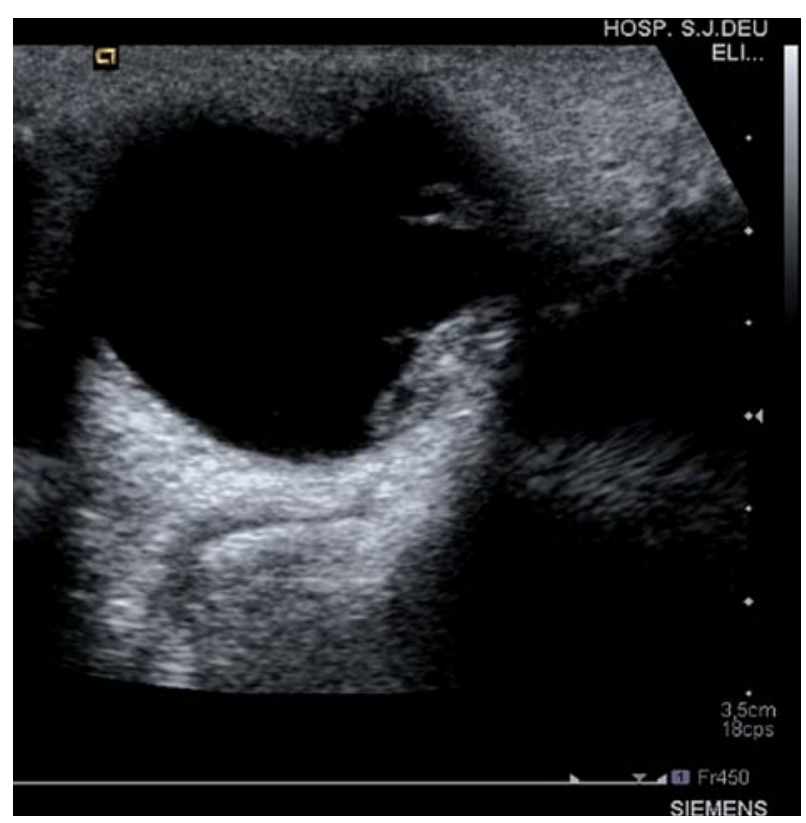

Fig. 2: Ecografía ocular que muestra una masa intraocular heterogénea sin evidencia de calcificación.

una determinación de lactato deshidrogenada (LDH) cuya tasa en humor acuoso/suero que fue de 4. No se detectaron eosinófilos ni anticuerpos antitoxocara en humor acuoso. Se estableció el diagnóstico de retinoblastoma del ojo izquierdo y se decidió la enucleación con implante de una prótesis suturada a los músculos rectos. El estudio anatomopatológico confirmó la presencia de un retinoblastoma difuso con invasión parcial del iris, cuerpo ciliar, coroides y esclera (figs. 4-6). Además se completó el estudio de extensión con aspirados de médula ósea y una punción lumbar que resultaron negativas.

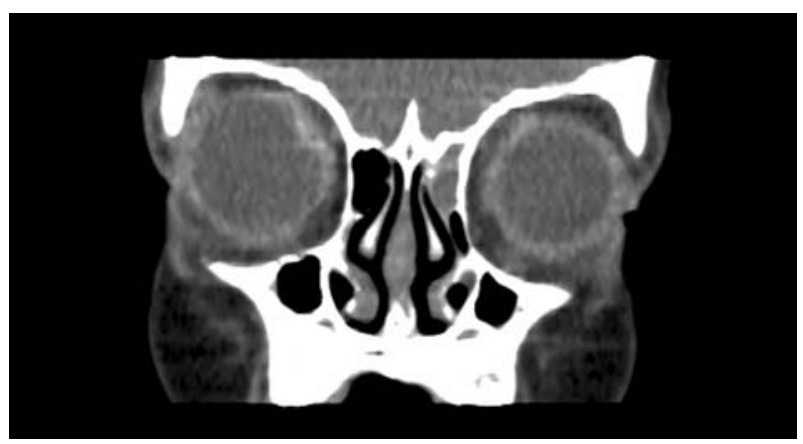

Fig. 3: Tomografía computerizada orbitaria en la que se detecta una lesión intraocular nasal con una discreta calcificación. 


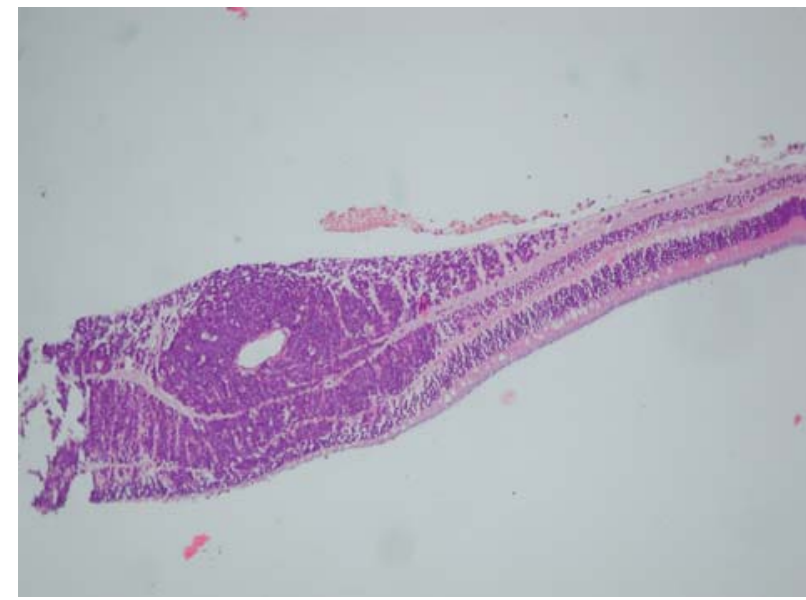

Fig. 4: Imagen anatomopatológica con tinción de hematoxilina-eosina $(10 x)$ de la invasión retiniana masiva por las células tumorales.

Se clasificó el caso como de riesgo histopatológico medio debido a la invasión de cámara anterior y esclera sin afectación del nervio óptico postlaminar y se iniciaron 6 ciclos de quimioterapia con vincristina $\left(1,5 \mathrm{mg} / \mathrm{m}^{2}\right)$ etopósido $\left(150 \mathrm{mg} / \mathrm{m}^{2}\right)$ y carboplatino $\left(560 \mathrm{mg} / \mathrm{m}^{2}\right)(1)$. El tratamiento se completó sin complicaciones.

El estudio genético de mutaciones en el gen RB fue negativo. Cuatro años después del tratamiento el paciente está sano. El ojo derecho es normal y usa una prótesis ocular externa bien tolerada.

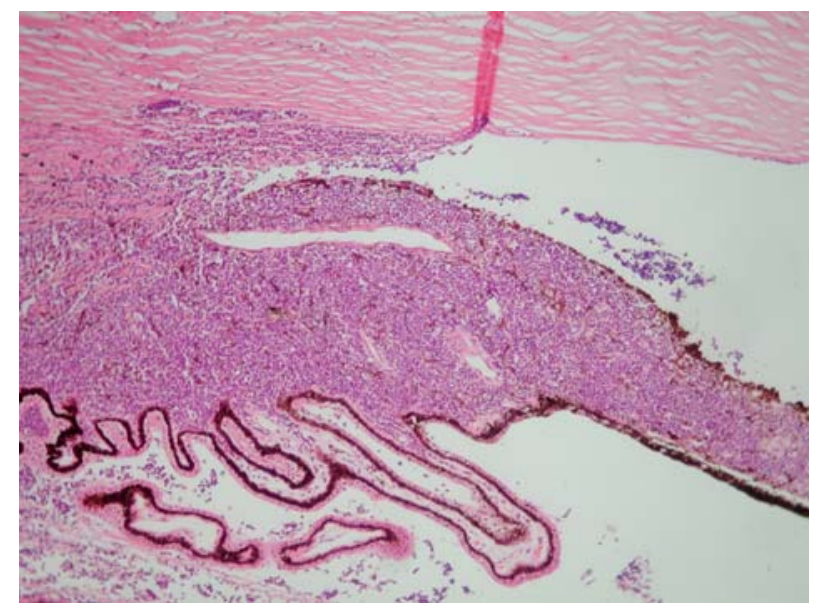

Fig. 5: Invasión tumoral del iris, cuerpo ciliar y esclera. Tinción de hematoxilina-eosina $(20 x)$.

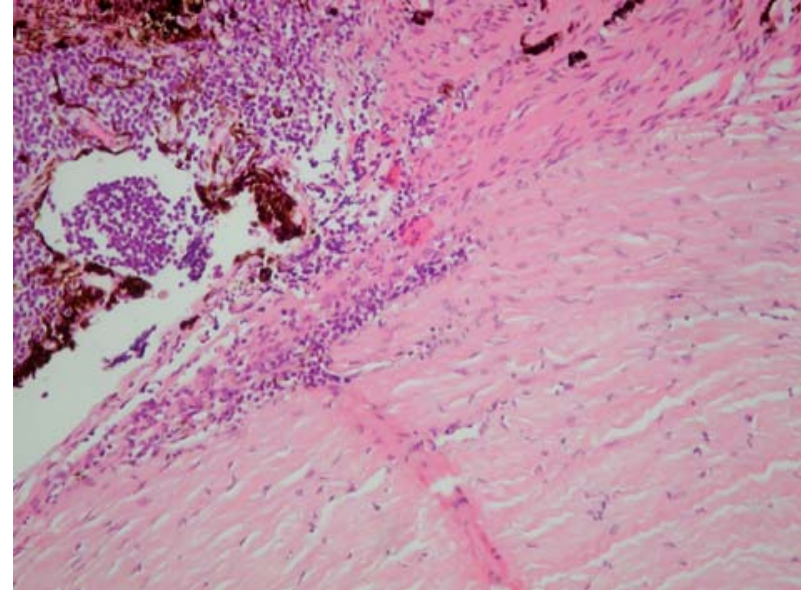

Fig. 6: Detalle de un foco tumoral intraescleral. Tinción de hematoxilina-eosina $(40 x)$.

\section{DISCUSIÓN}

Los signos clásicos de presentación de un retinoblastoma son leucocoria y estrabismo. La presentación como inflamación ocular puede ocurrir en un 1-3\% de los casos, generalmente asociada a la relativamente rara variante de retinoblastoma infiltrante difuso. Esta variante, generalmente unilateral, se presenta en niños mayores, alrededor de los 4 años de edad, a diferencia de las otras formas de retinoblastoma con una media de edad al diagnóstico de 18 meses (5).

Histológicamente estos tumores invaden difusamente la retina sin formar una masa tumoral. Los signos clínicos suelen ser: tyndall, pseudohipopión, quemosis conjuntival, hemovítreo y vitritis que dificultan la exploración del fondo de ojo. El diagnóstico inicial en estos casos suele ser de uveítis. Las calcificaciones pueden no estar presentes o no ser detectables mediante resonancia, tomografía computerizada o ecografía, que pueden detectar un engrosamiento retiniano difuso $(2,5)$. En estos casos tan infrecuentes puede ser de utilidad un aspirado de humor acuoso. No existen grandes series en la literatura médica que evalúen este procedimiento y sólo disponemos de descripciones de casos clínicos aislados. El procedimiento se realiza a través de córnea clara para evitar la diseminación de células tumorales y debe reservarse para casos en los que no se puede llegar a un diagnóstico mediante las técnicas no invasivas. El estudio citológico es diagnóstico si se detectan células tumorales, sin embar- 
go su escaso número y la dificultad de su proceso produce con frecuencia falsos negativos (3).

Las determinaciones enzimáticas en humor acuoso son una buena alternativa en estos casos: La lactato deshidrogenasa (LDH) es un enzima glucolítico que aparece a altas concentraciones en células con alta tasa metabólica. Normalmente su concentración en suero y en humor acuoso es baja y el ratio de LDH entre humor acuoso y suero es inferior a 1.0 en pacientes que no tienen retinoblastoma. Niveles elevados de LDH son sugestivos de retinoblastoma, pero no patognomónicos: se han descrito niveles elevados de LDH en pacientes con enfermedad de Coats, hipema traumático y otras patologías no tumorales (4). Otros enzimas que participan en el ciclo de la glucólisis como la fosfoglucosa isomerasa (PGI) y la enolasa neuronal específica (NSE) podrían ser también de utilidad aunque la experiencia sobre su uso es limitada. Recientemente se ha propuesto la cuantificación en humor acuoso de la expresión de la GD2 sintasa, un marcador de las células derivadas de la cresta neural, para el diagnóstico de retinoblastoma. Los niveles de PGI, al igual que los de $\mathrm{LDH}$, se detectan mediante espectrofotometría automática, una técnica habitual en todos los laboratorios. Los valores de NSE requieren técnicas de análisis radioinmunométrico o enzimoinmunoanálisis disponibles comercialmente; para la detección de GD2 sintasa se utilizan técnicas de PCR mucho más complejas. Todas estas enzimas tienen una elevada sensibilidad, cercana a $100 \%$ sin embargo ninguna está exenta de falsos positivos $(4,5)$.

Ante cualquier niño con uveítis, hipema, hipopión, hemovítreo o desprendimiento de retina deberíamos descartar la posibilidad de retinoblastoma mediante la valoración por un oftalmólogo experto así como con ecografía ocular y/o tomografía computerizada. El uso de punción-biopsia y los estudios enzimáticos en humor acuoso pueden ser de utilidad pero se deberían reservar sólo para los casos más dudosos debido al riesgo de diseminación tumoral (5).

\section{BIBLIOGRAFÍA}

1. Chantada GL, Dunkel IJ, de Dávila MT, Abramson DH. Retinoblastoma patients with high risk ocular pathological features: who needs adjuvant therapy? Br J Ophthalmol 2004; 88: 1069-1073.

2. Read RW, Zamir E, Rao NA. Neoplastic masquerade syndromes. Surv Ophthalmol 2002; 47: 81-124.

3. Howard GM, Ellsworth RM. Differential diagnosis of retinoblastoma. A statistical survey of 500 children. II. Factors relating to the diagnosis of retinoblastoma. Am J Ophthalmol 1965; 60: 618-621.

4. Felberg NT, McFall R, Shields JA. Aqueous humor enzyme patterns in retinoblastoma. Invest Ophthalmol Vis Sci 1977; 16: 1039-1046.

5. Shields CL, Ghassemi F, Tuncer S, Thangappan A, Shields $J A$. Clinical spectrum of diffuse infiltrating retinoblastoma in 34 consecutive eyes. Ophthalmology 2008; 115: 22532258 